\title{
LO PRESCRIPTIBLE Y LO IMPRESCRIPTIBLE EN LAS NORMAS CONSTITUCIONALES DEL ESTADO PLURINACIONAL DE BOLIVIA. UN ANÁLISIS A PARTIR DEL MARCO DE LOS DERECHOS HUMANOS
}

\author{
WHAT IS AND WHAT IS NOT SUBJECT TO STATUTE OF LIMITATIONS IN THE \\ CONSTITUTIONAL RULES OF THE PLURINATIONAL STATE OF BOLIVIA. AN \\ ANALYSIS FROM THE HUMAN RIGHTS FRAMEWORK
}

\author{
Juan Beimar Paye Mendoza ${ }^{1}$ \\ Universidad Privada Franz Tamayo \\ El Alto - Bolivia \\ https://orcid.org/0000-00019521-0892 \\ beimarpaye@gmail.com
}

\begin{abstract}
RESUMEN
Los tratados y convenios internacionales en materia de derechos humanos generan parámetros para categorizar lo que es prescriptible y lo que es imprescriptible en las legislaciones locales. Los institutos jurídicos de la prescripción e imprescriptibilidad son generalmente utilizados en la protección de los derechos humanos, y no en beneficio de los Estados. El presente artículo versa en un sustancioso análisis y una crítica constructiva de lo imprescriptible en favor del Estado Boliviano, tal como en el caso de delitos de corrupción y en materia tributaria, debido a que es no compatible con los tratados y convenios internacionales en materia de derechos humanos.
\end{abstract}

\section{PALABRAS CLAVES}

Prescripción, imprescriptibilidad, derechos humanos, seguridad jurídica, retroactividad.

\begin{abstract}
International human rights treaties and conventions create parameters to determine what is and what is not subject to statute of limitations in domestic laws. The legal principle of statute of limitations is generally used in the protection of human rights, and not for the benefit of the States. The purpose of this paper is to present a substantive analysis and constructive criticism of what is not subject to statute of limitations, hence favoring the Bolivian State, such as cases of crimes of corruption and tax matters. These cases are not compatible with international treaties and conventions on human rights.
\end{abstract}

\section{KEYWORDS}

Statute of limitations, human rights, legal security, retroactivity

1 Abogado y Politólogo. Maestrante en Derecho Constitucional y Procesal Constitucional por la Universidad Mayor de San Andrés. Ex abogado procesalista de las Fuerzas Armadas de Bolivia y el Servicio de Impuestos Nacionales de Bolivia, ex asesor legal del Consejo de la Magistratura de Bolivia. Actualmente trabaja como Docente Universitario. 


\section{INTRODUCCIÓN}

El establecimiento de los institutos jurídicos de prescripción e imprescriptibilidad dentro de las legislaciones nacionales pueden convertirse en un parámetro para reconocer el abordaje del principio de seguridad jurídica, y si estos se encuentran armonizados a los tratados y convenios internacionales en materia de derechos humanos, con la finalidad de proteger, respetar y garantizar la vigencia efectiva de los derechos.

En strictu sensu, los derechos humanos son "un conjunto de derechos subjetivos que corresponden universalmente a todas las personas por el solo hecho de serlo" (Vásquez, 2021, p. 263), y para su reconocimiento debemos partir desde la dignidad humana como elemento intrínseco que posee todo individuo, debido a que su naturaleza se centra en la realización existencial de su sentido -ser-, involucrando el entendimiento y exigencias de poder clasificar a los derechos humanos dentro de un contexto donde predomine la moral y el respeto igualitario. (Portugal, 2021).

En coherencia con Ferrajoli (1999) expresa que los derechos humanos "son derechos fundamentales, todos aquellos derechos subjetivos que corresponden universalmente a todos los seres humanos en cuanto dotados del status de personas, de ciudadanos o personas con capacidad de obrar" (p.37), quiere decir, que los derechos humanos no solamente actúan como derechos subjetivos, sino también como garantías individuales, sociales y constitucionales en su haber. En ese sentido, los derechos humanos como disciplina autónoma poseen características esenciales para su realización en la sociedad, tales como: universalidad, interdependencia, indivisibilidad y progresividad. (Vásquez, 2021)

Por ello, los instrumentos jurídicos en materia de derechos humanos, parten desde la concepción de la dignidad del ser humano, pues, la dignidad no solo amerita el término de -valor- y -principiossino también es un dínamo de los derechos inalienables. Estos generan parámetros para categorizar lo que puede establecerse como prescriptible y lo imprescriptible, sin omitir la aplicación de los principios generales del Derecho, como el principio de seguridad jurídica.

En el presente artículo, se analizará la restructuración del sistema jurídico boliviano, donde se establece un bloque de constitucionalidad que reconoce la aplicación preferente de los tratados internacionales de derechos humanos más favorables, que pueden ser interpretados en favor de las personas y no en sí favor del Estado, en ese entendido, algunas normas constitucionales de Bolivia pueden ser sujetas del control de convencionalidad para verificar la compatibilidad de estas con los instrumentos internacionales en materia de derechos humanos.

\section{LA PRESCRIPCIÓN Y LA IMPRESCRIPTIBILIDAD}

Un instituto jurídico muy allegado al tiempo es la prescripción, el cual se lo define como "un medio para adquirir un derecho o de liberarse de una obligación por causa del tiempo" (Ackerman , Ferrer, Piña, \& Rosatti, 2012, p. 285), pero no todos los derechos se adquieren por prescripción, sino tan solo algunos derechos reales, $y$, por otra parte, se pueden extinguir por el transcurso del tiempo no solo las obligaciones, sino toda clase de derechos, tanto del derecho privado como del derecho público.

Esta definición permite bifurcar dos tipos de prescripción, de una parte, una que se conoce como prescripción adquisitiva (adquiero derechos por causa del tiempo), y de otra parte, prescripción extintiva o liberatoria (me libero de obligaciones por causa del tiempo). Tanto la prescripción 
adquisitiva o usucapión, y la prescripción extintiva o liberatoria tienen su origen en el Derecho Civil, específicamente en el Derecho Romano, toda vez que la prescripción adquisitiva en su naturaleza jurídica, es un modo adquirir la propiedad y otros derechos reales, y la prescripción extintiva o liberatoria, es un modo de extinguir derechos patrimoniales u obligaciones, el cual produce la liberación del deudor frente a su acreedor. Fonseca ( 2004).

Ahora bien, sobre la prescripción extintiva o liberatoria, que si bien su génesis emana dentro del derecho privado, este instituto fue extrapolándose a otras áreas del derecho público, así tenemos; la prescripción penal, la prescripción fiscal, la prescripción administrativa, entre otros, en donde el sujeto activo no solamente es una persona particular o colectiva, sino también puede ser el Estado (Da Rin, 2020), donde el sujeto pasivo (los ciudadanos) pueden liberarse del ius puniendi o derecho de juzgar del Estado, esto por causa de la inacción estatal durante un plazo razonable, lógica inspirada en la idea de que un derecho no puede permanecer indefinidamente sin ser ejercitado, situación que provocaría inseguridad e incertidumbre en las relaciones jurídicas, ya que "todas las instituciones la prescripción es la más necesaria al orden social” (Rodríguez, 2012, p. 114).

En cambio, lo imprescriptible, "es un término que significa como aquello que no puede perderse por prescripción" (Cabanellas de Torres, 1993, p. 153), consiguientemente, un derecho no perderá validez por el transcurso del tiempo. Este marco conceptual, permite entender que hay derechos que no pueden perecer o morir por el transcurso del tiempo, como son los derechos humanos de una persona, como el derecho a la vida, a la libertad, a la salud, a la propiedad, estos no pueden extinguirse (Da Rin, 2020) que tiene su origen en el derecho anglosajón clásico donde la regla de derecho estaba expresada por nullum tempus occurit regis (el tiempo no corre para el Rey), esto quiere decir entonces que la acción podía iniciarse en cualquier momento después de la comisión del delito que no prescribía. (Abastoflor, 2021).

El instituto jurídico de la imprescriptibilidad se universaliza por medio de la figura del genocidio, el cual surgió luego de la segunda guerra mundial y se precisó en los tribunales de Núremberg como el hecho de exterminar a una raza o a un grupo humano, consiguientemente, conforme los tratados y convenios internacionales actuales son imprescriptibles los crímenes de guerra y los crímenes de lesa humanidad, por el carácter grave que tienen dentro de los derechos humanos. (Huertas, 2012)

Así como hay derechos y delitos que no pueden prescribir por el transcurso del tiempo, existen también bienes que son catalogados como imprescriptibles, como son los bienes públicos, ya que según la connotada jurista argentina Bellotti (2009) establece que "las cosas públicas del Estado son inenajenables, inembargables e imprescriptibles e inembargables". (p. 89).

Bajo dicho análisis, los derechos humanos y los bienes del Estado son catalogados como imprescriptibles, es decir no pueden extinguirse por causa del tiempo, estos dos sujetos de derecho, tanto la persona (natural o jurídica) como el Estado, tienen momentos de confrontación entre lo que puede ser prescriptible y lo que es imprescriptible, esto generalmente ocurre en materia penal y tributaria, como se analizará más adelante; el tiempo juega un rol protagónico en establecer un puente entre lo que es prescriptible para las personas y lo que es imprescriptible para el Estado.

\section{EL TIEMPO Y EL PRINCIPIO DE SEGURIDAD JURÍDICA}

Uno de los fines del Derecho es otorgar seguridad y orden social a las personas, a través de institutos legales que permitan regular el transcurso del tiempo, generando mecanismos legales para el justo ejercicio de los derechos, así como el cumplimiento efectivo de las obligaciones. 
La seguridad jurídica, como valor de cualquier ordenamiento jurídico, tiene su fundamento en lo que se conoce como Estado de Derecho, o también un Estado que se subordina a la Ley o al Derecho, es decir, el principio de la seguridad jurídica se opone al azar, a las arbitrariedades; y ya que el Derecho es un orden, una forma de vida, el Derecho tiene que exigir que sea posible la existencia de esa vida social. Es decir, el Derecho en sí mismo supone una certeza jurídica, y el transcurso del tiempo puede ser una causa, entre otras, de que el contenido jurídico de un supuesto de Derecho tienda a diluir y difundir el principio de la seguridad jurídica. (Paniagua, s.f, p.205)

Por consiguiente, la seguridad jurídica es el valor de un orden social, donde pueda existir respeto por parte del Estado a los hechos consolidados por el transcurso del tiempo, es decir, que el sujeto que garantiza la seguridad jurídica es ineludiblemente el Estado, y el sujeto que recibe la protección es ineludiblemente las personas, y no así en forma inversa.

\section{LA PRESCRIPCIÓN COMO DERECHO HUMANO Y LA IMPRESCRIPTIBILIDAD EN FAVOR DE LOS DERECHOS HUMANOS}

La positivización de los derechos humanos aparece como un -concepto legal- debido a su primer reconocimiento como atributo inherente de las personas naturales en las primeras declaraciones: La Declaración de Independencia de los EUA (1776), la Declaración de los Derechos del Hombre y del Ciudadano (Francia, 1789) y la Declaración Universal de los Derechos Humanos (1948), destacando a la dignidad humana como un atributo esencial para su división; sin embargo, para entenderlos debe hacerse un estudio multidisciplinario que analicen los derechos humanos y su transición con la democracia. (Vásquez, 2021)

Ahora bien, debido a su transcendencia, los Estados se han visto en la necesidad de reafirmar normas ius cogens en materia de derechos humanos y someterse a determinadas competencias para efectivizar el cumplimiento de los tratados internacionales, quiere decir que los Estados partes firmantes proceden a adoptar medidas internas que garanticen la vigencia efectiva de estos, a través de elaboración de leyes y políticas públicas. En coherencia con Gardenmia (2016) de esta manera, resulta indispensable promover el cumplimiento de obligaciones internacionales que propicie, a su vez, una red de implementación uniforme que sirva para hacer efectivo el valor de las normas de derechos humanos en un determinado territorio.

Por ejemplo, la Declaración Universal de Derechos Humanos ${ }^{2}$, acto que contiene derechos que ha establecido un hito histórico en la protección de las personas humanas, este documento gira bajo cuatro características fundamentales, el primero que los derechos humanos son universales, que significa que por el solo hecho de ser seres humanos todos tenemos derechos sin importar nuestras características personales; el segundo, que los derechos humanos son imprescriptibles, esto significa que no pueden ser quitados nunca porque su validez es perpetua; el tercero, que los derechos humanos son inalienables, esto significa que no los podemos ceder a nadie y el último que los derechos humanos son irrenunciables, porque ninguna persona puede renunciar a sus derechos. (Recursostic, n.d.) En su artículo 1 señala que "Todos los seres humanos nacen libres e iguales en dignidad y derechos y, dotados como están de razón y conciencia, deben comportarse fraternalmente los unos con los otros."

2 Adoptada y proclamada por la Asamblea General en su resolución 217 A (III), de 10 de diciembre de 1948. 
Seguidamente, la Declaración Americana de los Derechos y Deberes del Hombre ${ }^{3}$ en su respectivo preámbulo señala que "Todos los hombres nacen libres e iguales en dignidad y derechos y, dotados como están por naturaleza de razón y conciencia, deben conducirse fraternalmente los unos con los otros." También, el Pacto internacional de Derechos Civiles y Políticos ${ }^{4}$ y Pacto Internacional de Derechos Económicos, Sociales y Culturales $^{5}$ en sus respectivos preámbulo señalan que: "considerando que, conforme a los principios enunciados en la Carta de las Naciones Unidas, la libertad, la justicia y la paz en el mundo tienen por base el reconocimiento de la dignidad inherente a todos los miembros de la familia humana y de sus derechos iguales e inalienables"; al referirse también a la dignidad humana de los integrantes de la familia humana.

El paradigma constitucional que viven los actuales Estados Latinoamericanos permite que los tratados e instrumentos internacionales en materia de derechos humanos se constituyan como valores axiológicos en sus Constituciones, toda vez que aquellos Estados que hayan participado en la suscripción de la Convención Americana de Derechos Humanos ${ }^{6}$ se encuentran obligados aplicar con preferencia los derechos humanos más favorables para las personas.

Podemos encontrar los parámetros legales para entender el significado de lo prescriptible y lo imprescriptible en la Convención Americana sobre Derechos Humanos, también conocido como el Pacto de San José de Costa Rica, que en su artículo 8 numeral 1) establece:

1. Toda persona tiene derecho a ser oída, con las debidas garantías y dentro de un plazo razonable, por un juez o tribunal competente, independiente e imparcial, establecido con anterioridad por la ley, en la sustanciación de cualquier acusación penal formulada contra ella, o para la determinación de sus derechos y obligaciones de orden civil, laboral, fiscal o de cualquier otro carácter.

La categoría del tiempo nos da un parámetro legal para establecer lo que es prescriptible en favor de los derechos humanos, es decir, de que toda persona tiene derecho a recibir un proceso justo dentro de un plazo razonable, en las materias como penal, civil, laboral, fiscal e inclusive de cualquier otro carácter, en donde el sujeto a recibir protección son las personas (naturales o jurídicas) y no así el Estado (Abastoflor, 2021), porque el Estado no es sujeto de derechos humanos, consiguientemente, el tiempo puede ser utilizado como un parámetro de puro derecho en favor de los derechos humanos, mismos que no pueden ser omitidos por los ordenamientos jurídicos, esto para resguardar que las personas naturales o jurídicas sean juzgadas dentro de plazos razonables, y estos no queden a la deriva de un juzgamiento indeterminado. (Portugal, 2021)

Una de las hipótesis del presente radica en establecer que los derechos humanos tienen relación con la prescripción en favor de la protección de los derechos de las personas y en castigo a la negligencia que puede haber por parte del Estado, esto bajo el criterio de que la praescriptio introducta est odio negligentiae, non favore praescribentis. ${ }^{7}$

Empero, el derecho de juzgar del Estado no puede prescribir en todos los casos, estos se encuentran establecido en los siguientes instrumentos legales:

3 Aprobada en la Novena Conferencia Internacional Americana en Bogotá, Colombia, 1948.

4 Adoptado y abierto a la firma en la Asamblea General en su resolución 2200 A (XXI), de 16 de diciembre de 1966.

5 Adoptado y abierto a la firma en la Asamblea General en su resolución 2200 A (XXI), de 16 de diciembre de 1966.

6 Suscrita, tras la Conferencia Especializada Interamericana de Derechos Humanos, el 22 de noviembre de 1969 en la ciudad de San José en Costa Rica y entró en vigencia el 18 de julio de 1978.

7 La prescripción se introdujo más bien en contra de la negligencia que en favor de quien prescribe. 
La Convención sobre la imprescriptibilidad de los crímenes de guerra y de los crímenes de lesa humanidad ${ }^{8}$, establece en su artículo I, que los crímenes siguientes son imprescriptibles, en cualquiera que sea la fecha en que se hayan cometido:

a) Los crímenes de guerra según la definición dada en el Estatuto del Tribunal Militar Internacional de Nuremberg, de 8 de agosto de 1945, y confirmada por las resoluciones de la Asamblea General de las Naciones Unidas 3 (I) de 13 de febrero de 1946 y 95 (I) de 11 de diciembre de 1946, sobre todo las "infracciones graves" enumeradas en los Convenios de Ginebra de 12 de agosto de 1949 para la protección de las víctimas de la guerra;

b) Los crímenes de lesa humanidad cometidos tanto en tiempo de guerra como en tiempo de paz, según la definición dada en el Estatuto del Tribunal Militar Internacional de Nuremberg, de 8 de agosto de 1945, y confirmada por las resoluciones de la Asamblea General de las Naciones Unidas 3 (I) de 13 de febrero de 1946 y 95 (I) de 11 de diciembre de 1946, así como la expulsión por ataque armado u ocupación y los actos inhumanos debidos a la política de apartheid y el delito de genocidio definido en la Convención de 1948 para la Prevención y la Sanción del Delito de Genocidio aun si esos actos no constituyen una violación del derecho interno del país donde fueron cometidos.

Los crímenes de lesa humanidad son graves violaciones a los derechos humanos, constituyéndose en crímenes internacionales, que pueden ser perseguibles en cualquier tiempo y lugar, es decir imprescriptibles. Consiguientemente, en materia de derechos humanos la imprescriptibilidad únicamente se puede limitar a los crímenes contra la humanidad, en esta línea Ziffer (2005) destaca que la prescripción solo debe ser sacrificada en situaciones excepcionales, por cuanto resulta inadmisible que la persecución de cualquier delito pueda ser efectuada sin límite alguno, haciendo a un lado el derecho a que el proceso penal sea tramitado dentro de un plazo razonable. (Abastoflor, 2021).

En muchos casos la Corte Interamericana ha ampliado la imprescriptibilidad con el término de graves violaciones a los derechos humanos, que puedan contravenir el Derecho Internacional y puedan ofender el alto grado de la dignidad humana y quedar en impunidad, esto permite entender que la imprescriptibilidad es una excepción para iniciar el castigo a otros seres humanos que hayan cometido violaciones a los derechos humanos, pero la regla es que lo prescriptible es en favor de una persona cuando se encuentra sometido a un proceso, mismo que debe ser juzgado dentro de un plazo razonable.

Por otro lado, hay algunos Estados que en materia de delitos de corrupción han establecido la imprescriptibilidad de los mismos, al respecto es importante señalar las siguientes normas jurídicas que regulan esta situación: La Convención de las Naciones Unidas Contra la Corrupción ${ }^{9}$ en su artículo 29 establece:

Cada Estado Parte establecerá, cuando proceda, con arreglo a su derecho interno, un plazo de prescripción amplio para iniciar procesos por cualesquiera de los delitos tipificados con arreglo a la presente Convención y establecerá un plazo mayor o interrumpirá la prescripción cuando el presunto delincuente haya eludido la administración de justicia. (Naciones Unidas Oficina contra la droga y el delito, 2004, p. 23)

8 Adoptada y abierta a la firma, ratificación y adhesión por la Asamblea General en su resolución 2391 (XXIII), de 26 de noviembre de 1968.

9 Fue adoptada el 31 de octubre de 2003 por la Asamblea General de las Naciones Unidas con la Resolución 58/4 y con fecha de mayo de 2020. 
El artículo precedente es concreto en otorgar un margen de discrecionalidad a cada Estado parte para que determine un plazo de prescripción para el juzgamiento de delitos de corrupción cometidos por funcionarios públicos, por consiguiente, no se evidencia en la convención precedente ni tampoco en otra parte de la Convención de las Naciones Unidas Contra la Corrupción (Da Rin, 2020), una disposición expresa que otorgue a los Estados discrecionalidad para determinar la imprescriptibilidad de esta clase de delitos.

Asimismo, el artículo décimo noveno de la Convención Interamericana contra la Corrupción ${ }^{10}$, determina, "con sujeción a los principios constitucionales, al ordenamiento interno de cada Estado y a los tratados vigentes entre los Estados Partes, el hecho de que el presunto acto de corrupción se hubiese cometido con anterioridad a la entrada en vigor de la presente Convención, no impedirá la cooperación procesal penal internacional entre los Estados Partes. La presente disposición en ningún caso afectará el principio de la irretroactividad de la ley penal ni su aplicación interrumpirá los plazos de prescripción en curso relativos a los delitos anteriores a la fecha de la entrada en vigor de esta Convención." (Naciones Unidas, 2004, p.30)

Consiguientemente, la imprescriptibilidad solamente puede instituirse en las legislaciones nacionales cuando existan graves violaciones a los derechos humanos en el marco de lo establecido por el Derecho Internacional, principios que son expuestos en los Convenios de las Naciones Unidas, que no otorgan facultades discrecionales para legislar la imprescriptibilidad de otra clase de delitos y facultades del Estado.

En tal sentido, los tratados y convenios internacionales en materia de derechos humanos establecen la imprescriptibilidad en favor de las personas, esto con el fin de materializar y proteger sus derechos humanos, pero no establecen o dan entender la imprescriptibilidad en favor del Estado, excepto en graves violaciones a los derechos humanos, como excepción, pero por regla el Estado es sujeto de que puedan prescribir sus facultades en resguardo de los principios en materia de derechos humanos.

\section{LO IMPRESCRIPTIBLE EN LAS NORMAS CONSTITUCIONALES DE BOLIVIA}

Bolivia, ha tenido una refundación constitucional el año 2009, con la promulgación de la actual Constitución Política del Estado Plurinacional de Bolivia, constituyéndose como un Estado Unitario Social de Derecho Plurinacional Comunitario, libre, independiente, soberano, democrático, intercultural, descentralizado y con autonomías. El Estado Plurinacional de Bolivia, además, se funda en la pluralidad y el pluralismo político, económico, jurídico, cultural y lingüístico, dentro de un proceso integrador del país ${ }^{11}$.

Las innovaciones jurídicas dentro de la Constitución boliviana son el resultado de problemáticas sociales históricas, esto incluye la inclusión del concepto de lo plurinacional como reconocimiento a la diversidad cultural y étnica de Bolivia (Da Rin, 2020), la protección de los derechos laborales, la lucha contra la corrupción, el fortalecimiento del rol protagónico del Estado en la vida pública, el establecimiento de garantías constitucionales y un amplio catálogo de derechos fundamentales, por mencionar solamente algunos.

10 Adoptada en la tercera sesión plenaria, celebrada el 29 de marzo de 1996.

11 Constitución Política del Estado de Bolivia (CPE) promulgada el año 2009. 
Con relación a la imprescriptibilidad a favor del Estado en la Constitución Política de Bolivia (Constitución Política del Estado Bolivia, 2009) se tienen los siguientes artículos que establecen la imprescriptibilidad a favor del Estado:

Artículo 112. Los delitos cometidos por servidores públicos que atenten contra el patrimonio del Estado y causen grave daño económico, son imprescriptibles y no admiten régimen de inmunidad.

Artículo 113. La Ley solo dispone para lo venidero y no tendrá efecto retroactivo, excepto en materia laboral, cuando lo determine expresamente a favor de las trabajadoras y de los trabajadores; en materia penal, cuando beneficie a la imputada o al imputado; en materia de corrupción, para investigar, procesar y sancionar los delitos cometidos por servidores públicos contra los intereses del Estado; y en el resto de los casos señalados por la Constitución.

Artículo 123. La ley sólo dispone para lo venidero y no tendrá efecto retroactivo, excepto en materia laboral, cuando lo determine expresamente a favor de las trabajadoras y de los trabajadores; en materia penal, cuando beneficie a la imputada o al imputado; en materia de corrupción, para investigar, procesar y sancionar los delitos cometidos por servidores públicos contra los intereses del Estado; y en el resto de los casos señalados por la Constitución.

Artículo 324. No prescribirán las deudas por daños económicos causados al Estado.

La Asamblea Constituyente de Bolivia en el año 2006 ha establecido los mecanismos constitucionales para que los servidores públicos, como también las personas naturales o jurídicas que causen daño o ilegítimamente se beneficien del Estado, no puedan quedar impunes por el instituto jurídico de la prescripción, esto puede responder a los altos porcentajes de delitos de corrupción y como muchos de ellos quedan impunes.

Al respecto, dentro del artículo 123 de la Constitución Política del Estado de Bolivia cuando establece que las normas son retroactivas en materia laboral cuando existan normas a favor de las trabajadoras y de los trabajadores, en materia penal para beneficiar a la imputada o al imputado, se identifica la aplicación del principio pro hómine en la interpretación y aplicación directa de los derechos humanos, para que se pueda materializar la realización máxima de los derechos de la persona.

En esa misma línea, se considera cuando la norma es retroactiva para investigar, procesar y sancionar los delitos cometidos por servidores públicos contra los intereses del Estado, esta retroactividad podría catalogarse a favor del Estado, pero no en sí a favor de los ciudadanos, donde generalmente las normas son retroactivas cuando benefician a las personas, pero genera una duda razonable que las normas en este caso sean retroactivas para beneficiar el rol del Estado en su persecución a los delitos de corrupción, esto generaría una observación a la aplicación del principio de seguridad jurídica y de retroactividad a la norma.

Consiguientemente, las convenciones de la ONU e Interamericana contra la corrupción, no otorgan ninguna facultad para que los Estados miembros, puedan establecer la imprescriptibilidad de los delitos de corrupción en sus legislaciones internas; por lo cual, realizando un control de convencionalidad, los Estados que determinen la imprescriptibilidad de estos ilícitos, estarían 
actuando de forma incompatible y contraria a las normas del derecho internacional. (Revollo Morales, 2018)

Otro de los casos, donde se presenta el instituto de la imprescriptibilidad en favor del Estado, es en el Código Tributario boliviano (Servicio de Impuestos Nacionales de Bolivia, 2020, p. 42) en su artículo 59 que establece:

\section{ARTÍCULO $59^{\circ}$ (Prescripción)}

I. Las acciones de la Administración Tributaria prescribirán a los cuatro (4) años en la gestión 2012, cinco (5) años en la gestión 2013, seis (6) años en la gestión 2014, siete (7) años en 2015, ocho (8) años en gestión 2016, nueve (9) años en la gestión 2017, y diez (10) años a partir de la gestión 2018, para:

1. Controlar, investigar, verificar, comprobar y fiscalizar tributos.

2. Determinar la deuda tributaria.

3. Imponer sanciones administrativas.

II. Los términos de prescripción precedentes se ampliarán en tres (3) años adicionales cuando el sujeto pasivo o tercero responsable no cumpliera con la obligación de inscribirse en los registros pertinentes o se inscribiera en un régimen tributario diferente al que le corresponde.

III. El término para ejecutar las sanciones por contravenciones tributarias prescribe a los cinco (5) años.

\section{LA FACULTAD DE EJECUTAR LA DEUDA TRIBUTARIA DETERMINADA, ES IMPRESCRIPTIBLE.}

Al respecto, el establecimiento de la imprescriptibilidad en el artículo 59 del Código Tributario en caso de ejecutar la deuda tributaria, puede estar amparado en el artículo 324 de la Constitución donde establece que las deudas por daños económicos causados al Estado no prescriben, aspecto que fue establecido después de la vigencia de la actual Constitución, empero, es importante recordar que la determinación de la imprescriptibilidad en este caso a favor del Estado, debería pasar por un filtro convencional de los derechos humanos, toda vez que la prescripción y más aún en materia tributaria, puede convertirse en un medidor de la aplicabilidad del principio de seguridad jurídica y la materialización de los derechos humanos, en consecuencia, esta determinación de la imprescriptibilidad de una de las acciones del Estado no se encuentra dentro de las excepciones para establecer la imprescriptibilidad conforme los tratados internacionales en materia de Derechos Humanos, una de las hipótesis que han sido demostradas en el presente artículo.

En consecuencia, dicha categoría del tiempo como puente entre el derecho de prescripción por parte de las personas y la imprescriptibilidad a favor del Estado en algunas materias del derecho público, podría ser útil en establecer plazos razonables para lo que puede determinarse como imprescriptible por parte de las legislaciones nacionales, esto a efectos de que estas legislaciones sean compatibles con las convenciones de las Naciones Unidas, sin dejar de lado la impunidad de los delitos ni la efectividad del derecho de cobro por parte del Estado, sino que estas facultades puedan vigorizarse durante un tiempo prudente a efectos de que el Estado sea un instrumento más efectivo en su ius puniendi sin omitir los principios generales del Derecho. 
Por tanto, la prescripción liberatoria y los tratados internacionales en materia de derechos humanos son compatibles cuando es en favor de las personas, pero no así en favor de las prerrogativas del Estado para juzgar, excepto en delitos graves contra los derechos humanos, por consiguiente, las hipótesis planteadas en el presente requieren ser discutidas con el objeto de generar una cultura que resguarde los derechos humanos a efectos de construir diariamente los Estados de Derecho en Latinoamérica.

\section{CONCLUSIONES}

1. Los tratados y convenios internacionales en materia de derechos humanos generan parámetros para categorizar lo que es prescriptible y lo que es imprescriptible en las legislaciones locales, a efectos de que no se puedan omitir la aplicación de los principios generales del Derecho, como el principio de seguridad jurídica.

2. Los institutos jurídicos de la prescripción e imprescriptibilidad son generalmente utilizados para la protección de los derechos humanos de las personas y no así para que el Estado pueda beneficiarse de sus alcances en su derecho a juzgar, excepto cuando se traten de graves violaciones a los derechos humanos, lo contrario implicaría la incompatibilidad de sus normas con los tratados internacionales.

3. La Constitución Política boliviana contiene innovaciones jurídicas interesantes que han avanzado en el reconocimiento de institutos jurídicos en favor de los ciudadanos, empero, existen normas jurídicas que determinan la imprescriptibilidad y la retroactividad de la ley a favor del Estado, estas son susceptibles de control de convencionalidad, toda vez que se duda sobre la compatibilidad de estas con los tratados internacionales en materia de derechos humanos, en el entendido de que la prescripción solo es excepcional para delitos graves en materia de derechos humanos, y no así para otro tipo de materias en el derecho público y privado.

4. La prescripción liberatoria, es un instituto jurídico que permite garantizar la armonía social, puede llegar a convertirse en un catalizador para que los sujetos activos lleguen a ejercer con efectividad sus derechos en un tiempo prudente, por otro lado, la imprescriptibilidad como instituto jurídico, debe ser utilizado para coadyuvar en el cumplimiento de lo que es justo, sin dejar de lado que los sujetos de derechos son las personas, y no así el Estado, aunque sea representante de todos nosotros, muchas veces la mala utilización de estas figuras jurídicas, pueden llegar a ser atentatorios a lo que realmente es importante, que son las personas y sus derechos.

\section{REFERENCIAS}

- Abastoflor, F. (2021). Imprescriptibilidad y retroactividad de los Derechos y Garantías Constitucionales en la Constitución boliviana. Revista Lex, 4(12), 103-116. https://doi. org/10.33996/revistalex.v4i12.75

- Ackerman , M., Ferrer, F., Piña, R., \& Rosatti, H. (2012). Diccionario Jurídico. Buenos Aires: Culzoni Editores.

- Asamblea Constituyente de Bolivia. (2009). Constitución Política del Estado Plurinacional de Bolivia. Gaceta Oficial del Estado Plurinacional del Estado Plurinacional de Bolivia.

- Cabanellas de Torres, G. (1993). Diccionario jurídico elemental. Heliasta S.R.L.

- Da Rin , N. (2020). La imprescriptibilidad del derecho a obtener reparación integral de las víctimas de Lesa Humanidad. Derechos. Acción, 14(14), 547-557. https://doi. org/10.24215/25251678e368 
- Ferrajoli, L. (1999). Derechos y Garantías. La Ley más débil. Editorial Trotta.

- Ferrajoli, L. (2010). Democracia y garantismo.Trotta.

- Fonseca, C. (2004). La prescripción extintiva y la caducidad. Universidad de los Andes Facultad de Derecho.

- Huertas, O. (2014). El principio de imprescriptibilidad de los delitos de lesa humanidad y su aplicación en el ordenamiento jurídico colombiano, un estudio desde los derechos humanos y la interpretación jurídica. Revista de Derecho y Ciencias Sociales, 7(1), 7. 199 - 127.

- Organización de las Naciones Unidas. (11 de noviembre de 1970). Convención sobre la imprescriptibilidad de los crímenes de guerra y de los crímenes de lesa humanidad. Obtenido de la Oficina del Alto Comisionado de Naciones Unidas: https://www.ohchr.org/SP/ Professionallnterest/Pages/WarCrimes.aspx

- Paniagua Redondo, R. (sf). La Institución de la prescripción liberatoria en materia de obligaciones internacionales en el Derecho Internacional Público.

- Portugal, J. (2021). La transgresión de la imprescriptibilidad en los delitos de corrupción. Revista Lex, 4(12), 90-102. https://doi.org/10.33996/revistalex.v4i12.74

- Recursostic. (s.f.). http://recursostic.educacion.es/secundaria/edad/4esoetica/quincena5/ quincena5_contenidos_4.htm\#: :text=Los $\% 20$ derechos $\% 20$ humanos $\% 20$ est $\%$ C3\%A1n $\% 20$ recogidos, Unidas $\% 20$ en $\% 20$ el\%20a\%C3\%B10\%201948.\&text=Los $\% 20$ derechos $\% 20$ humanos $\% 20$ son\%20imprescriptibles,jam\%C3\%A1s\%

- Revollo Morales, N. M. (2018). Los delitos de corrupción y la viabilidad de establecer un régimen especial de prescripción. Estudios Constitucionales.

- Rodríguez, J. (2012). La regulación de la prescripción extintiva y la caducidad. Revista de la Facultad de Derecho de Montevideo, pp. 113 - 142.

- Servicio de Impuestos Nacionales de Bolivia. (2020). Ley 2492 Código Tributario Boliviano y Decretos Reglamentarios, texto ordenado, complementado y actualizado al 31/01/2020. Gerencia de Servicio al Contribuyente y Cultura.

- Vásquez, D. (2011). Los Derechos Humanos, la democracia representativa y los mecanismos sociales de garantías. Notas para una reflexión. Revista Latinoamericana de Política, Filosofía y Derecho, 31 (1), 173-191.

- Vásquez, D. y Serrano, S. (2013). Los derechos en acción. Obligaciones y principios de derechos humanos. Consejo Editorial de FLACSCO México.

- Vásquez, D. (2021). Impunidad y Derechos Humanos. Instituto de Investigaciones Jurídicas, UNAM.

- Ziffer, P. (2005). El principio de legalidad y la imprescriptibilidad de los delitos de lesa humanidad. Editores del Puerto.

Fecha de recepción : 21 de octubre de 2021

Fecha de aceptación : 23 de noviembre de 2021 